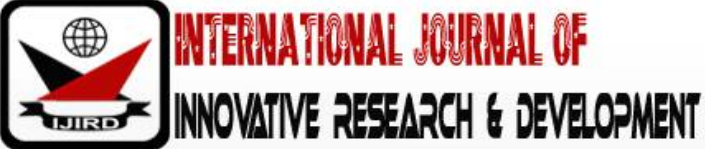

ISSN 2278 - 0211 (Online)

\section{Heresies and Hopes for Scamper Instructional Strategy on Nigerian Secondary School Students' Academic Achievement in Biology}

\author{
Dr. Moses Olanrewaju Afuwape \\ Senior Lecturer, Department of Science and Technology Education \\ Olabisi Onabanjo University, Ago- Iwoye, Ogun State, Nigeria \\ Salaam Ibrahim Oladoja \\ Principal, Department of Science and Technology Education \\ Olabisi Onabanjo University, Ago- Iwoye, Ogun State, Nigeria
}

\begin{abstract}
:
Creativity and innovation in teaching effectiveness has become the major focus of concerned educators and researchers for effective problem solving. Nigerian Educational Research and Development Council (NERDC) in the curriculum for Biology encourages teachers to teach for creative and critical thinking potentials in the students which is the main focus of SCAMPER instructional strategy.

This study investigated the impact of SCAMPER instructional strategy for enhancing Nigerian secondary school students' academic achievement in Biology. It also examined the interaction effect of cognitive style on the students' academic achievement in Biology. Three hypotheses guided the study and tested at 0.05 level of significance.

The study adopted a Pre-test, Post-test Quasi-experimental design with 2x2 factorial matrix. Purposive sampling technique was used to pick two intact classes of senior secondary school 1 consisting of 117 Biology students in Ogun State of Nigerian. Biology Achievement Test (BAT, $r=0.75$ ) and Cognitive style scale of 0.67 reliability were used for data collection. Data was analysed with descriptive statistics and inferential tools of Analysis of Covariance (ANCOVA). Findings of the study revealed no significant main effect of instructional strategy on students' academic achievement in Biology. However,the study revealed a significant main effect of cognitive style on students' academic achievement in Biology. But instructional strategy and cognitive style did not reveal significant academic achievement in Biology

It is therefore, suggested that SCAMPER strategy should be used by the Biology teachers for the effective teaching- learning process.
\end{abstract}

Keywords: SCAMPER strategy, cognitive style, gender, achievement in biology

\section{Background}

Science education is employed in the individual's decision-making on scientific processes and principles and it allows the individual to participate in discussions on scientific matters and to develop skills to produce ideas on the matters. Science education also promotes scientific activities that are carried out by all people as part of their everyday life (Akcay\&Yager, 2010; Afuwape \& Oriola, 2017).

There is no denying the fact that Biology occupies a very sensitive position in science disciplines. The very important nature and relevance of Biology made it a subject offered by both science and arts students at the secondary school level in Nigeria. It is one of the science subjects students should pass at the senior secondary school level so as to qualify to offer some science courses at tertiary level of education. like Medicine, Agricultural Science and so on. The main objectives of Biology programme according to Federal Ministry of Education are to prepare students to acquire. "meaningful and relevant knowledge in Biology that is necessary for successful living in a scientific and technological world and also to make room for technological advancement" others include:

- Ability to apply scientific knowledge to everyday life in matters of personal and community health and agriculture.

- Ability of the learners to the development of an awareness of the environment.

- Higher education (NERDC, 2014).

In pursuance of the stated objectives, the contents and context of the curriculum are intended to provide a modern Biology course as well as to meet the needs of the learner and the society through relevance and functionality in its contents, method, processes and application (NERDC, 2014).

It is however, very disheartening that despite the role and much emphasis being placed on Biology as a subject, students at secondary school level of education are still performing poorly in the subject. This has been an issue of great concern to stakeholders in education, most especially those in the field of science education. This is perhaps showing in the 
outcome of West African Examination Council general performance of students in Biology from 2009-2016 with particular reference to Ogun State of Nigeria as shown in Table 1.

\begin{tabular}{|c|c|c|c|c|c|}
\hline Year & Total Entry & $\begin{array}{c}\text { No Of Credit } \\
\text { Passed }\end{array}$ & $\begin{array}{c}\text { \% of credit } \\
\text { Passed }\end{array}$ & No of Failure & \% of Failure \\
\hline 2009 & 10,337 & 3,654 & 35.50 & 6,683 & 64.50 \\
\hline 2010 & 10,059 & 2,268 & 22.50 & 7,791 & 77.50 \\
\hline 2011 & 8,534 & 2,652 & 31.00 & 5,882 & 69.00 \\
\hline 2012 & 8,934 & 1,518 & 17.00 & 7,416 & 83.00 \\
\hline 2013 & 6,874 & 1,986 & 29.00 & 4,888 & 71.00 \\
\hline 2014 & 9,026 & 3,581 & 39.65 & 5,445 & 60.35 \\
\hline 2015 & 6,128 & 2,686 & 40.45 & 3,442 & 59.55 \\
\hline 2016 & 6,894 & 2,270 & 32.90 & 4.624 & 67.10 \\
\hline
\end{tabular}

Table 1: Students Performance Analysis in the May/ June Biology from 2009 - 2016

Grades Lower Than $\mathrm{A}_{1}-\mathrm{C}_{6}$ (I.E. Distinction and Credit) Are Regarded as Failure

Source: West African Examination Council, Research and Statistics Unit (Ogun State Branch Controller,2016)

Table 1 shows the statistics of Biology results in May/ June Secondary School Certificate Examination (SSCE) from 2009 to 2016. From the Table, it could be concluded that performance of students in Biology has not been impressive and the failure rate is much higher and alarming. Students' performance in Biology has consistently been reportedly low over the years in Nigeria especially in Senior Secondary School Certificate Examination (WAEC Chief Examiners' Report, 2016).

The most recent of these arrays of reports, WAEC Chief Examiners' report (2015) stated that students' poor performance in Biology can be linked to their inability to state correctly the difference between the excretion in flowering plants and excretion in human beings. This is a good example of paucity of the creative and critical thinking potentials in the examinees for the year. Another striking example is that the students were making a diagram of the Nitrogen Cycle instead of the Carbon Cycle. This is an indication that they were not equipped in the skill of re-arrangement of facts and concepts. Aside the foregoing, the WAEC Chief examiners' report (2016) attributed the dismal performance in Biology to some concepts that appear to be difficult for the students to answer correctly. The difficult content areas are Ecology, Excretory System, Transport System and Genetics.

However, studies have shown that many teachers do not promote critical thinking in their classrooms (Olurinola, 2015, Oludipe, 2015; Awobodu, 2016.). Kurah (2015) found that majority of Biology teachers use lecture method in teaching which usually encourages memorization of facts. On his part, Ayuba (2016) reported that most science teachers in secondary schools were using lecture method and this resulted in students' poor academic achievement.

The goal of this study is to identify whether scamper can positively enhance both creative and critical thinking skills in students' academic achievement in Biology. This is to determine its feasibility as a thinking tool that can be used in teaching and learning higher order thinking skills.SCAMPER (Directed Brainstorming) can be seen as an entertaining and practical teaching approach that increases creative thinking (Harman \&Celikler, 2015). Yagci (2012) defined SCAMPER as "a sort of practical and entertaining brainstorming technique which is inherent in the discussion method, ensuring implementation of the method by putting it into practice"

This originated as a technique initially used by Eberle(1971) to enhance creativity of students. For this strategy, a concept or idea is chosen and then changed and developed through brainstorming. To do so, questions are directed to the child. The questions encourage the child to think in such a way that he/ she has not been familiar with before. Such questions are, in a sense, a driving force to allow them acquire different thinking skills. They improve thinking in children, encouraging them to discover. The SCAMPER also teaches howto think in a flexible fashion and to break patterns (Ylldız and İsrael, 2001).

Another important variable of interest in this study is cognitive style. Cognitive styles are psychological constructs which describe an individual's mode of information perception, organization and representation. Cognitive style refers to consistency in perception, cognitive representation and abstract valuation. Anchor (2001) explained that cognitive style is a unique way of organizing external stimuli that characterize an individual's learning behavior. Okwo, F.A and Otubah (2007), opined that it is the psychological construct which describes individuals' mode of information, perception, organization and representation. The cognitive style of an individual is the individual's psychological disposition which affects his/ her mode of perceptual and conceptual organization or classification of attainment task. It is the process of knowing, understanding and learning by students. Salami (2000) observed that students' achievement depends on their cognitive style. In the contribution of Tella(2008), cognitive style is sine-qua-non to the evaluation of students' achievement in learning and a significant and potential predictor of future achievement. Katrina (2006), reported that cognitive style as the ability to carry out abstract thinking. In consequence, this study will investigate the main impact of SCAMPER strategy and cognitive style on students' academic achievement in Biology and also investigate the interaction effect of scamper strategy and cognitive style on students' academic achievement in Biology. 


\subsection{Hypotheses}

The following null hypotheses were formulated and tested at 0.05 level of significance:

- Ho1: There is no significant main effect of SCAMPER strategy on students' academic achievement in Biology.

- Ho2: There is no significant main effect of SCAMPER style on students' academic achievement in Biology.

- Ho3: There is no significant interaction effect of SCAMPER strategy and cognitive style on students' academic achievement in Biology.

\section{Methodology}

\subsection{Research Design}

This research study adopted pre-test, post-test control group quasi experimental design using 2x2 factorial matrix. The design includes one experimental group which was exposed to SCAMPER strategy (SS). While the control group was exposed to the Conventional (CM) method and moderating variables was students' cognitive style at two levels (Analytical and Non-Analytical). The dependent variable was the students' academic achievement in Biology. The schematic representation for the design was shown below

$\begin{array}{cccc}\text { A } & 0_{1} & \mathrm{X}_{1} & 0_{2} \\ \mathrm{~B} & 0_{3} & \mathrm{X}_{2} & 0_{4}\end{array}$

$\mathrm{O}_{1} \& \mathrm{O}_{3}=$ Pre-test Observations

$\mathrm{O}_{2} \& \mathrm{O}_{4}=$ Post-test Observations

$\mathrm{X}_{1}=$ Experimental treatment (SCAMPER Strategy)

$\mathrm{X}_{2}=$ Placebo treatment (Conventional method)

$\mathrm{A}=$ Experimental group

$\mathrm{B}=$ Control group

\subsection{Target Population} of Nigeria.

The target population for the study consisted of all SS1 Biology students in public secondary schools in Ogun State

\subsection{Sample and Sampling Technique}

The sample for the study consisted two public schools in Ifo Local Government Area of Ogun State. In both Schools, the intact class of Senior Secondary 1 (SS1) offering Biology were used for the study. One hundred and seventeen (117) students from the schools were used. The sample was selected by using purposive sampling technique. The two schools were purposively selected based on the following:

- Schools where students have not been exposed to the selected topics

- Schools that possess trained educational degree holders with not less than five years' experience in teaching Biology.

- Schools that have consistently been presenting candidates for Senior Secondary Certificate Examination (SSCE).

\subsection{Instrumentation}

The following three instruments were used for this study,

- $\quad$ Biology Achievement Test (BAT)

- $\quad$ Cognitive Style Test (CST)

- $\quad$ Scamper Instructional Strategy guide (SISG)

The BAT measured students' achievement in Biology. It has a multiple-choice test with lettered A-D options, consisting of 25-items. The items selected are from the past questions of Senior School Certificate Examination (WAEC and NECO) from 2009 to 2016 in under listed topics- Basic Ecological Concepts, Functioning Ecosystem and Energy transformation in Nature. The topics that are contained in the BAT items measured knowledge, comprehension and higher-level order of objectives as shown in the table of specification.

The twenty-five items that survived the item analysis procedure constituted the Biology Achievement Test (BAT). The twenty-five items were presented to two experienced Biology teacher for the face and content validity of the items and their corrections and suggestions were effected and used to produce the final version of the instrument. The 25- item BAT was then administered on a sample of thirty (30) SS1 students different from the main study and the result was 0.75 using split-half method.

The cognitive style test is a Multiple- Choice items, developed by Anton E. Lawson, Arizona State University in August 2000.The test was adapted to measure students' cognitive style. It contains twenty (20) analytical items. Therefore, the students who scored above mean average was categorized as analytical students (Field independent) while the students who scored below mean average was categorized as non-analytical students (Field dependent). The adapted version of instruments was presented to two experts in the area of evaluation for perusal in order to re-establish its content validity. The experts certified the instrument suitability for the level of students under study (SS1), the adequacy of the statements in relation to the content and the language used in terms of clarity. The observations of the experts were noted and used to improve the test.

The 20 items modified CST was administered on a sample of 30 (SS1) students outside the main study but similar in characteristics to the students for whom the instrument was intended in order to re-establish its reliability for the 
present study and it was later re-administered after two weeks on the same students. A reliability of 0.67 was obtained using test retest method.

The different responses were scored and summed up separately for each student. In this study, students with analytical cognitive were those who scored above mean average in all responses. While non- analytical cognitive students were those who scored below mean average in all responses.

2.5. Scamper Instructional Strategy Guide

The tasks in the experimental group were presented using the SCAMPER strategy which was developed by (Eberle 1996). In the process of guiding students to be creative and critical in their thinking during Biology classes.

\subsection{Conventional Method}

This is control group, as such, the students were not exposed to any other treatment aside from the way the teacher had always been teaching them (Conventional Method). The teacher prepared his lesson notes and taught his lesson as usual.

\section{Results and Discussion}

\begin{tabular}{|c|c|c|c|c|}
\hline Group & Cognitive style & Mean & Std. Deviation & N \\
\hline Experimental & Analytical & 8.35 & 2.690 & 31 \\
\cline { 2 - 5 } Control & Non-Analytical & 7.61 & 2.150 & 33 \\
\cline { 2 - 5 } & Total & 7.97 & 2.436 & 64 \\
\cline { 2 - 5 } & Analytical & 7.43 & 2.098 & 28 \\
\cline { 2 - 5 } & Non-Analytical & 7.84 & 2.838 & 25 \\
\cline { 2 - 5 } & Total & 7.62 & 2.459 & 53 \\
\hline
\end{tabular}

Table 2: Descriptive Statistics According to Instructional Strategy Group and Cognitive Style

Table 2 shows that there are 64 students participated in the experimental group, out of which 31 are analytical while 33 are non-analytical students. In the control group, there are 53 student participants out of which 28 are analytical and 25 are non- analytical.

\begin{tabular}{|c|c|c|c|c|c|}
\hline $\begin{array}{c}\text { Source of } \\
\text { Variation }\end{array}$ & Sumof Squares & DF & Mean Square & F & .Sig \\
\hline Main Effect & 399.422 & 1 & 399.422 & 75.611 & .000 \\
\hline $\begin{array}{c}\text { Covariates } \\
\text { (Pretest) }\end{array}$ & 53.348 & 1 & 53.348 & 10.099 & .002 \\
\hline Strategy & 2.264 & 1 & 2.264 & .429 & .514 \\
\hline Cognitive Style & .294 & 1 & .294 & .056 & .002 \\
\hline $\begin{array}{c}\text { 2 Way } \\
\text { interactions }\end{array}$ & & 1 & & & \\
\hline $\begin{array}{c}\text { Strategy* } \\
\text { Cognitive Style }\end{array}$ & 5.395 & 8 & 5.395 & 1.021 & .314 \\
\hline Explained & $121.341 \mathrm{a}$ & 108 & 15.168 & 2.871 & .006 \\
\hline Residual & 570.522 & 116 & 5.283 & & \\
\hline Corrected Total & 691.863 & & & \\
\hline
\end{tabular}

Table.3: Summary of Analysis of Covariance of Students' Academic Achievement in

Biology According to Strategy and Cognitive Style

Indicates Significant F at 0.05 Level, R Square =0.175, Adjusted R Square $=.114$

Table 3 presents the summary of the analysis of covariance (ANCOVA) test on the effect of teaching strategy and cognitive style on the students' academic achievement in Biology.

\subsection{Testing of Hypotheses}

\subsubsection{Hypothesis 1}

There is no significant main effect of SCAMPER strategy on students' academic achievement in Biology.The result shows non-significant main effect of instructional strategy $\left(\mathrm{F}_{(1,116)}=0.429, \mathrm{P}>0.05\right)$. This implies no significant difference in the mean post-test achievement scores of the students after exposure to SCAMPER strategy at 0.05 level of significance. As a result, the null hypothesis 1 is retained. 


\begin{tabular}{|c|c|c|c|c|c|}
\hline $\begin{array}{l}\text { Variable + Category } \\
\text { Teaching Strategy. }\end{array}$ & $\mathbf{N}$ & $\begin{array}{l}\text { Unadjusted } \\
\text { Deviation }\end{array}$ & Eta & $\begin{array}{c}\text { Adjustedfor } \\
\text { Independent+ } \\
\text { Covariates }\end{array}$ & Beta \\
\hline $\begin{array}{l}\text { 1. SCAMPER } \\
2 . \quad \text { Conventional } \\
\text { Method } \\
\text { Cognitive style } \\
\text { Analytical } \\
\text { Non-Analytical } \\
\text { Multiple R Squared } \\
\text { Multiple R }\end{array}$ & $\begin{array}{l}64 \\
53 \\
59 \\
58\end{array}$ & $\begin{array}{l}-0.157 \\
-0.189 \\
103 \\
-.105\end{array}$ & 0.043 & $\begin{array}{l}0.185 \\
0.153 \\
0.115 \\
0.117\end{array}$ & $\begin{array}{l}0.048 \\
0.095 \\
0.009\end{array}$ \\
\hline
\end{tabular}

Table 4: Multiple Classification Analysis of Students' Academic Achievement in Biology According to SCAMPER Strategy and Cognitive Style Levels

GRAND MEAN=7.940

The MCA, presented in Table 4 shows the mean post-test mean achievement scores of the students in the SCAMPER strategy and two levels of Cognitive style according to order of magnitudes as well as the contributions of the independent variables to the variance in the dependent variable. The result shows that with a grand mean of 7.940 , the students exposed to SCAMPER strategy recorded the higher adjusted mean achievement score of 8.125 (i.e. $7.940+.185$ ), while students exposed to conventional method recorded adjusted mean post-test achievement score of 8.093 (i.e. $7.940+$ 0.153). This outcome thus implies that the SCAMPER strategy with a higher adjusted mean post-test knowledge score is a better strategy for teaching and improving students' academic achievement in Biology.

The result in Table 4 further shows that the SCAMPER instructional strategy contributed $6.9 \%$ (Beta=0.069) of the variance in the students' academic achievement in Biology, using SCAMPER strategy while the independent and moderator variables jointly accounted for $9.5 \%$ (R Squared $=0.095$ ) of the variance in students' academic achievement in Biology. Hence, the strategy has little contribution to the students' academic achievement in Biology but not significant.

\subsubsection{Hypothesis 2}

There is no significant main effect of cognitive style on students' academic achievement in Biology. The result of the main effect of Cognitive style in Table3 shows a significant main effect of cognitive style on students' academic achievement in Biology. $\left(F_{(1,116)}=.056, \mathrm{P}<0.05\right)$. This outcome implies that there is significant difference between the post-test mean achievement scores obtained by analytical and non-analytical students in the Biology after exposure to SCAMPER and control method used in the study. As a result, null hypothesis 3 is rejected. However, the result of the multiple classification analysis (MCA) on Cognitive style in Table 4 showed that with a grand mean of 7.940, analytical students with adjusted mean post-test achievement score of 8.055 (i.e.7.940 +0.115) recorded lower mean academic achievement compared with non-analytical students with adjusted mean post-test academic achievement score of 8.057 (i.e.7.940+0.117). This outcome shows that the non-analytical students recorded higher adjusted post-test mean scores than the analytical students but the difference obtained in the mean post-test knowledge scores of analytical and nonanalytical students is not statistically significant at 0.05 level. The result in Table 4 further shows that Cognitive style as a moderating variable significantly contributed $4.8 \%$ of the variance in the students' academic achievement in Biology.

\subsubsection{Hypothesis 3}

There is no significant interaction effect of SCAMPER strategy and cognitive style on students' academic achievement in Biology. The result of the 2-way interaction effect of the strategy and Cognitive style in Table 3 shows no significant interaction effect of the instructional strategy and cognitive style on academic achievement of students in Biology $\left(\mathrm{F}_{(1,116)}=1.021, \mathrm{P}>0.05\right)$. This outcome implied that the students' mean post-test academic achievement scores after exposure to the SCAMPER and control method do not vary significantly between analytical and non-analytical students. This means that there is no significant difference in the mean post-test academic achievement scores of the analytical and non-analytical students exposed to SCAMPER and control Method. As a result, null hypothesis3 is retained. Hence, this can be concluded that there is no significant interaction effect of strategy and Cognitive style on students' academic achievement in Biology.

\section{Discussion of Findings}

\subsection{Impact of Instructional Strategy on Academic Achievement in Biology}

The findings showed no significant effect of instructional strategy on students' academic achievement in Biology. The plausible reason for this outcome might not be unconnected with the fact that the students exposed to the treatment (SCAMPER) have not been familiar with it and couple with the fact that the research assistant was not the one that conceived the study. Therefore, he might not use the strategy effectively and that may have contributed to the outcome of the findings. However, further analysis revealed that students exposed to SCAMPER strategy had higher adjusted mean post-test which is evidence that the strategy helped learners to form their own pattern of learning which eventually led to construction of new knowledge. This finding supports the Armstrong (2012); who have shown that students are expected to be able to construct their knowledge, studies and learning in a manner which prepares them for their chosen profession and improved students' investigative nature of science (Awobodu, 2016, Cuevas, Lee, Hart \&Dearktor, 2005). 
This finding agrees withOzyaprak (2016) in his study who indicated that using SCAMPER in creative training enhances participants' creative thinking abilities especially for divergent thinking. It also agrees with the study of Hamzah and Ruzlan (2016), who reported that experimental group exposed to the SCAMPER strategy had higher level of creativity than control group. This finding is equally corroborated by earlier findings ofKaytez\&Aytar (2016) who found that SCAMPER strategy is effective in revealing children's creative personality traits and behaviours. Accordingly, in increasing children's scores in the experimental group, activities within SCAMPER strategy that promote active participation and aim at featuring creativity are effective. This finding further supported the outcome of Alrowethy (2012) who revealed a significant difference (0.05) between the average scores of controls' group and experimental with respect to creative skills acquisition especially in favour of the experimental group. The result further reported that SCAMPER has important effect on flexibility, fluency and originality. In situations in which the level of overall cognitive load is extremely low, such as for high-knowledge learners studying very simple material or high knowledge learners studying complex material with unlimited time, SCAMPER strategy may become more effective.

This outcome has further strengthened the earlier findings of Toraman and Altun (2013) who confirmed that when the SCAMPER strategy is effectively applied, it enhances students' cognitive development in their learning of related subjects by providing them the motivation and opportunities to engage in creative thinking.

\subsection{Effect of Cognitive Style on Students' Academic Achievement in Biology}

The result of the main effect of cognitive style in Table 3 shows a significant main effect of cognitive style on students' academic achievement in Biology. This outcome implies that there is significant difference between the post-test mean achievement scores obtained by analytical and non-analytical students in Biology after exposure to SCAMPER and control method used in the study. The findings revealed that the non-analytical cognitive style students performed better than the analytical cognitive style students. The results of this study is consistent with the findings of Achor (2001) that cognitive style has a significant influence on student's academic achievement and improve their attitudinal disposition toward science concept. The findings are inconsistent with that of Oludipe (2014) who confirmed that cognitive style has significant influence on student's academic achievement and that the analytical cognitive style is higher in achievement compared to students with non-analytical cognitive style.

\section{Recommendations}

i. Biology teachers should begin to combine SCAMPER strategy with conventional method to enhance studentcentred environment to imbue principles of active participation, teamwork and independence geared towards advancing in knowledge acquisition in the students.

ii. Students learn differently based on cognitive style. Therefore, it is recommended that science teachers are adequately equipped with the skills needed to create an environment where all kinds of students can learn meaningfully, individually in a Biology class.

iii. Various groups of stakeholders should create opportunities for the training of secondary school teachers in the use of SCAMPER strategy in teaching Biology.

iv. Curriculum developers and planners should as a matter of urgency consider the implementation of SCAMPER strategy in the school curriculum.

v. Educational policy makers should take into consideration the desperate need for better policy, regulations and laws that are geared toward the attainment of more meaningful Biology education in Nigeria.

\section{References}

i. Afuwape, M.O., \& Oriola B.O. (2017) Skills in Basic Science and Technology for local Technology and Engineering and advanced Technology studies, 5(1),80-89,ISSN:2054-6351.Published by European - American Research institute, UK.

ii. Akcay, H., \& Yager, R.E. (2010) The impact of science/ Technology/ Society/ Teaching Approach on student learning in five domains. (JSET), 19:602-611.D01:10.1007/ S 10956010-9226.

iii. Alrowethy, M. (2012). The effectiveness of SCAMPER strategy on the teaching of sciences to develop of creative and thinking skills among gifted in the primary school at AL-Madinah Al-Munowarah. Unpublished doctoral dissertation, Taibahuniversity, Taibah, Saudi Arabia.

iv. Anchor, E.E (2001). Cognitive Correlates Physics Achievement of some Nigerian Secondary Students. Journal of Science Teachers Association of Nigeria 38(1\&2), 10-15.

v. Armstrong, J. S. (2012). Natural Learning in Higher Education. In H. Springer, Encyclopedia of the Sciences of Learning (pp. 1-10). Philadelphia, PA: University of Pennsylvania.

vi. Awobodu,V.Y. (2016). Problem-Based learning and Programmed instruction as strategies for enhancing learningoutcomes in Biology. Unpublished Ph.D. Thesis submitted to the Science and Technology Education Department, OlabisiOnabanjo University, Ago- Iwoye, Ogun State.

vii. Ayuba, B. (2016). Impact of peer Tutoring on the Academic Achievement in Sciences Among Secondary SchoolStudents WithinBauchi Metropolis. Unpublished B. Tech (Ed) Project, AbubakarTafawaBalewa University, Bauchi.

viii. Cuevas, P., Lee, O., Hart, J., \&Deaktor, R. (2005).Improving science inquiry with elementary students of diverse backgrounds. Journal of Research in Science Teaching, 42(3), 337-357.

ix. Eberle, B. (1971), SCAMPER: Games for imagination development, Buffalo, NY: DOK Publishing. Federal Ministry of Education (2014). National Curriculum for Senior Secondary School. Biology, Lagos: Published by NERDCp. 6 
x. Hamzah, M., \&Ruzlan M.D. (2016). The different impact of SCAMPER and CORT Programmes on creative thinkingamong Gifted and talented students. Asian Journal of Multidisciplinary studies, vol. 4, issue 12, November 2016.

xi. Harman, G., \& Celikler, D. (2015). The Effect of the SCAMPER Technique in Raising Awareness Regarding the Collection and Utilization of Solid Waste. Journal of education and Practice, 6 (10), 149-158.

xii. Katrina, L. (2006). Relationship among motivational goals, academic self-concept and academic Achievement, whatis Causal ordering? Research centre, University of Western Sydney, Australia.

xiii. Kaytez, N., \& Gungor Aytar, A. (2016). Analysis of the effect of SCAMPER Education Program on five-year-old children's creativity. Journal of Human Sciences, 13(3), NNN.doi: 10.14687/ jhs.v 13i3, 4037.

xiv. Kurah,J.R (2015). Teacher Factors influencing the implementation of Biology curriculum in Secondary Schools,Kaduna State. Unpublished M. ED Dissertation, Department of Science and Technology Education, University of Abuja.

xv. Oludipe, B.D. (2014). Cognitive style profile and Physics achievement of senior secondary School Students in Ogun-state. Journal of Education and practices 5(8)69-75.

xvi. Olurinola, O. D. (2015). Effects of Power Point and Multiple Mouse Presentation Media Junior Secondary School Students Learning Outcomes in Cultural and Creative Art. Unpublished Ph.D. Thesis submitted to the Department of Curriculum Studies and Instructional Technology, Olabisi Onabanjo University, Ago-Iwoye. pp. 30-35

xvii. Ozyaprak, M. (2016).The effectiveness of SCAMPER technique on creative thinking skills Journal for the Education of gifted Young scientists,.4(1),31-40.

xviii. Salami, 1.0. (2000). Effect of three instructional modes of student teachers' performance in Selected Teaching Skills.Unpublished Ph.D. Thesis, University of Ibadan.

xix. Tella, A. (2008). Relationship among demographic variables and Pupils' reasoning ability. Electronic Journal of research in Educational Psychology. 6(3), 709-728.

xx. Toraman, S. \&Altum, S. (2013)." Application of the six Thinking hats and SCAMPER techniques on the 7th grade

xxi. course unit" human and environment: An exemplary case study. Mevlana International Journal of Education, 3(4)166-185.

xxii. Yagci, E. (2012). A study on Parents' Opinions on directed brainstorming technique: SCAMPER. Journal of Faculty of Education Sciences,(43), 485-494. 